\section{ENCOURAGING OUTCOMES AFTER MITRAL VALVE REPAIR WITH THE \\ GEOFORM ANNULOPLASTY \\ RING. AN EXTRAORDINARY \\ RING OR A VERY GOOD \\ PATIENT SELECTION? \\ To the Editor:}

We read with great interest the results published by Timek and colleagues ${ }^{1}$ regarding the implantation of the GeoForm ring (Edwards Lifesciences Corporation, Irvine, Calif) for ischemic mitral regurgitation (MR). Surprisingly, according to the Kaplan-Meier curve, the freedom from recurrent $2+\mathrm{MR}$ at 4 years was $100 \%$ (see the original Figure 2). These formidable results differ from the almost $30 \%$ recurrent MR rate at 1 year reported in a recent trial. ${ }^{2}$ Timek and colleagues ${ }^{1}$ speculate whether the use of this specific ring, characterized by a greater reduction of the anteroposterior distance and the 3-dimensional elevation of the P2 segment, could be the main cause for these better outcomes.

We would like to highlight other reasons that could explain these diverging results. Whereas in the study of Timek and colleagues ${ }^{1}$ almost a third of patients had only $2+$ MR at the time of the operation, in the previously mentioned trial ${ }^{2}$ all patients had severe MR. Moreover, Timek and colleagues ${ }^{1}$ reported that a quarter of the surviving patients had no echocardiography beyond 6 months, and it is not known whether this subgroup

\footnotetext{
The Editor welcomes submissions for possible publication in the Letters to the Editor section that consist of commentary on an article published in the Journal or other relevant issues. Authors should: - Include no more than 500 words of text, three authors, and five references. - Type with double-spacing. - See http://jtcs.ctsnetjournals.org/misc/ifora.shtml for detailed submission instructions. - Submit the letter electronically via jtcvs.editorialmanager.com. Letters commenting on an article published in the JTCVS will be considered if they are received within 6 weeks of the time the article was published. Authors of the article being commented on will be given an opportunity of offer a timely response ( 2 weeks) to the letter. Authors of letters will be notified that the letter has been received. Unpublished letters cannot be returned.
}

could be associated with worse functional class or significant MR.

Nevertheless, from our point of view, there is a critical factor that can accurately predict recurrence of MR after a repair. Neither of the studies mentioned here accounted for this strong predictor, mitral leaflet tethering. Laplace's law (pressure is proportional to wall stress divided by radius of curvature) implies that once MR is initiated, end-diastolic left ventricular volume and wall stress increase in parallel with preload. The increase in load stress leads to further left ventricular remodeling, which culminates in a spiraling, selfperpetuating cycle of leaflet tethering. Recurrent MR after an initially successful mitral annuloplasty may be related to continuing left ventricular remodeling with its consequent increase in the tethering. ${ }^{3}$ Tethering can be quantified by echocardiographic measurements, such as interpapillary muscle distance, coaptation depth, and left ventricular enddiastolic index. Interestingly, in one report $^{3}$ more than $95 \%$ of patients with recurrent MR during a midterm follow-up period had previously demonstrated an interpapillary muscle distance of more than $20 \mathrm{~mm}$.

Thus although there is high evidence $^{3,4}$ that patient selection plays a key role in the recurrence of MR, neither of these studies ${ }^{1,2}$ reported the factors taken into account to select patients for repair. It is therefore likely that the main reason for this great divergence in results lies in the different criteria used to select patients as candidates for mitral ring annuloplasty.

Daniel Hernández-Vaquero, $M D, P h D^{a}$ Rocío Díaz, $M D^{a}$ César Morís, $M D, P h D^{b}$ ${ }^{a}$ Cardiac Surgery Department ${ }^{b}$ Department of Cardiology Heart Area Central University Hospital of Asturias Asturias, Spain

\section{References}

1. Timek TA, Hooker RL, Collingwood R, Davis AT, Alguire CT, Willekes CL, et al. Five-year real world outcomes of GeoForm ring implantation in patients with ischemic mitral regurgitation. J Thorac Cardiovasc Surg. February 21, 2014 [Epub ahead of print].

2. Acker MA, Parides MK, Perrault LP, Moskowitz AJ, Gelijns AC, Voisine P, et al, CTSN. Mitral-valve repair versus replacement for severe ischemic mitral regurgitation. $N$ Engl $J$ Med. 2014;370:23-32.

3. Roshanali F, Mandegar MH, Yousefnia MA, Rayatzadeh H, Alaeddini F. A prospective study of predicting factors in ischemic mitral regurgitation recurrence after ring annuloplasty. Ann Thorac Surg. 2007;84:745-9.

4. Gelsomino S, Lorusso R, Caciolli S, Capecchi I, Rostagno C, Chioccioli M, et al. Insights on left ventricular and valvular mechanisms of recurrent ischemic mitral regurgitation after restrictive annuloplasty and coronary artery bypass grafting. J Thorac Cardiovasc Surg. 2008;136:507-18.

http://dx.doi.org/10.1016/ j.jtcvs.2014.03.046

\section{Reply to the Editor:}

My colleagues and I greatly appreciate the thoughtful commentary provided by Hernández-Vaquero and colleagues on our study "Five-year real world outcomes of GeoForm ring implantation in patients with ischemic mitral regurgitation." $\mathrm{Al}$ though our clinical series offers encouraging results with the use of the GeoForm ring in patients with severe left ventricular (LV) dysfunction and ischemic mitral regurgitation, we agree that there is more in play than the reparative technique alone. Despite their paucity, the available clinical data on the use of the GeoForm ring deserve closer examination to interpret our results in the proper context. In the first published cohort of $74 \mathrm{pa}-$ tients implanted with the GeoForm ring, De Bonis and colleagues ${ }^{1}$ found that freedom from $2+$ or greater mitral regurgitation (MR) at 3.5 years was $75 \%$, but $2+$ or greater MR was present in only $9 \%$ of patients $(5 / 56)$ with symmetric leaflet tethering and central MR jets on preoperative echocardiography. Indeed, asymmetric leaflet tethering with restriction of the posterior was found to be the only independent predictor of recurrent 
$2+$ or greater MR. A recent German study $^{2}$ of 70 patients at 4 years reported an overall freedom from recurrence of mitral regurgitation grade $3+$ or greater of $92 \%$ and a freedom from $2+$ or greater $\mathrm{MR}$ of $71 \%$, corroborating the earlier report. Our current findings align with these results, although our echocardiographic follow-up was not complete and $31 \%$ of patients had only $2+$ MR preoperatively. Our patients had severely reduced LV function and predominantly central MR, which may be more reflective of greater symmetric $\mathrm{LV}$ and annular dilation. Patients with end-stage ventricles have been found to have more symmetric leaflet tethering and less jet asymetry. ${ }^{3}$ It is difficult to compare the outcomes of patients with ischemic MR treated with ring annuloplasty, because ischemic MR may be associated with relatively preserved LV function, localized posterolateral infarct, and asymmetric posterior leaflet tethering or with end-stage ischemic cardiomyopathy with significant annular and LV dilation, symmetric leaflet tethering, and a centrally oriented regurgitant jet. ${ }^{4}$ These extremes lie on a clinical continuum, both are associated with a "normal" appearing valve, and each is surgically corrected with undersized ring annuloplasty. We wholeheartedly agree with Hernández-Vaquero and colleagues that patient selection is paramount in optimizing surgical results, and as such we have chosen to restrict our use of the GeoForm prosthesis to patients with severe LV dysfunction, significant annular and chamber dilatation, and a central regurgitant jet. We believe that this form of ischemic MR is best treated with significant septolateral annular reduction, which is incorporated in the design of the GeoForm prosthesis. Although preoperative echocardiographic determination of leaflet tethering has been a focus of significant clinical research, leaflet and chordal tissue remodeling can also compensate for altered subvalvular alterations, ${ }^{5}$ and mechanical forces insufficient to affect valvular competency induce geometric leaflet remodeling and altered gene expression. ${ }^{6}$ Indeed, the unique adaptation of valvular tissue to ventricular remodeling is often forgotten when viewing echocardiographic studies of patients with end-stage dilated hearts and altered subvalvular geometry but little or no mitral regurgitation. The insightful analysis of the Asturias group has generated more questions than the limited answers our study can provide to the challenging problem of ischemic mitral regurgitation.

Tomasz Timek, MD Department of Cardiothoracic Surgery

Meijer Heart and Vascular Insitute at Spectrum Health Grand Rapids, Mich

\section{References}

1. De Bonis M, Tarmasso M, Grimalds A, Maisano F, Calabrese MC, Verzini A, et al. The GeoForm annuloplasty ring for the surgical treatment of functional mitral regurgitation in advanced dilated cardiomyopathy. Eur J Cardiothorac Surg. 2011; 40:488-95.

2. Guenzinger R, Schneider EP, Guenther T, Wolf P, Mazzitelli D, Lange R, et al. Three-dimensional valve repair-the better care? Midterm results of a saddle-shaped, rigid annuloplasty ring in patients with ischemic mitral regurgitation. J Thorac Cardiovasc Surg. 2014;148:176-82.

3. Kwan J, Shiota T, Agler DA, Popović ZB, Qin JX, Gillinov MA, et al. Geometric differences of the mitral apparatus between ischemic and dilated cardiomyopathy with significant mitral regurgitation: real-time three-dimensional echocardiography study. Circulation. 2003;107: 1135-40.

4. Timek TA, Miller DC. Another multidisciplinary look at ischemic mitral regurgitation. Semin Thorac Cardiovasc Surg. 2011;23:220-31

5. Chaput M, Tournoux F, Hua L, Hua L, Guerrero JL, Vlahakes GJ, et al. Mitral leaflet adaptation to ventricular remodeling: occurrence and adequacy in patients with functional mitral regurgitation. Circulation. 2008;118:845-52.

6. Dal-Bianco JP, Aikawa E, Bischoff J, Guerrero JL, Handschumacher MD, Sullivan S, et al. Active adaptation of the tethered mitral valve: insights into a compensatory mechanism for functional mitral regurgitation. Circulation. 2009; 120:334-42.

http://dx.doi.org/10.1016/ j.jtcvs.2014.04.016

\section{EFFECT OF RIGHT VENTRICULAR FREE WALL VENTRICULOTOMY ON RIGHT VENTRICULAR FUNCTION: IS THAT THE CORRECT QUESTION? \\ To the Editor:}

Lee and colleagues ${ }^{1}$ recently reviewed the effects of limited versus conventional right ventriculotomy on subsequent right ventricular (RV) dilation and dysfunction in patients with tetralogy of Fallot who develop pulmonary regurgitation (PR) after transannular repair. No long-term benefits were seen after limited right ventriculotomy. The logic behind this strategy stems from the premise that the free wall RV incision generates dysfunction, with a corresponding hypothesis that late RV function would benefit from restricting the $\mathrm{RV}$ incision to less than $1 \mathrm{~cm}$ or avoiding it with transatrial and pulmonary artery approaches. Determining the reasons for such failure to offset long-term dysfunction requires analyzing relationships between RV structure and function. I therefore ask whether to use limited versus conventional right ventriculotomy is the right question. Questions about the advantages of limited versus conventional right ventriculotomy arose when knowledge of the relationships between RV structure and function was absent. We now know that the septum occupies $40 \%$ of ventricular muscle mass, dominates RV function, and is protected by standardized myocardial protection techniques in adults. $^{2}$

The helical heart model of Torrent-Guasp shows that the RV free wall is predominantly composed of transverse fibers (basal loop) that cause circumferential compression (Figure 1), whereas the septum contains only helical fibers (apical loop) that produce twisting and shortening. Approximately $80 \%$ of RV function derives from longitudinal strain or shortening ${ }^{3}$ and is quantified by tricuspid annular plane systolic 